\title{
Modeling lumber recovery in relation to selected tree characteristics in jack pine using sawing simulator Optitek
}

\author{
Shu-Yin ZHANG*, Que-Ju TONG \\ Forintek Canada Corp., 319 rue Franquet, Sainte-Foy, Québec, Canada G1P 4R4
}

(Received 26 May 2004; accepted 31 August 2004)

\begin{abstract}
End uses and product recovery are important considerations in forest management decision-making. This study intended to develop general tree-level lumber volume recovery models for jack pine. A sample of 154 jack pine trees collected from natural stands was scanned to obtain 3-D stem geometry for sawing simulation under two sawmill layouts, a stud mill and a random mill with optimized bucking, using sawing simulator Optitek. Three model forms were chosen to describe the quantitative relationship between simulated lumber volume recovery and tree characteristics. It was found that lumber volume recovery of individual trees from both sawmills could be well estimated from DBH using a second-order polynomial equation. Adding tree height into the model resulted in a small but significant improvement in the goodness of the model. Adding tree taper into the model that already included DBH and tree height no longer improved the goodness significantly. The power function form involving only DBH or both DBH and tree height as variables was also found to be suitable for the stud mill; exponential forms were least suitable. The second-order polynomial model with DBH alone was the most suitable model when inventory records DBH only, while the second-order polynomial model and the power model involving two variables (DBH and tree height) for the random mill and the stud mill, respectively, were better when both $\mathrm{DBH}$ and tree height are available.
\end{abstract}

tree characteristics / sawing simulation / Optitek / lumber recovery / general model

Résumé - Modélisation du rendement en sciages en relation avec certaines caractéristiques du pin baumier en utilisant le logiciel de simulation Optitek. L'utilisation finale et le rendement en produits sont des considérations importantes dans la prise de décision en aménagement forestier. Cette étude vise à développer des modèles généraux de rendement en volume au niveau de l'arbre du pin baumier. Un échantillon de 154 arbres de sapin baumier récoltés dans des peuplements naturels a été scanné pour obtenir la géométrie 3-D des tiges pour effectuer la simulation selon deux configurations d'usine, soit une scierie de bois de colombage et une usine variable avec tronçonnage optimisé avec le simulateur de sciage Optitek. Trois formes de modèles ont été choisies pour décrire la relation quantitative entre le rendement en sciage simulé et les caractéristiques de l'arbre. Il semble que le rendement en sciage d'arbres individuels provenant des deux scieries peut être bien estimé à partir du DHP en utilisant une équation polynomiale de deuxième ordre. L'ajout de la hauteur de l'arbre aux résultats du modèle est une petite amélioration, mais tout de même significative pour la validité du modèle. Toutefois, l'ajout du défilement de l'arbre à un modèle incluant déjà le DHP et la hauteur de l'arbre n'améliore pas significativement la validité. Les équations de fonction puissance impliquant seulement le DHP ou le DHP et la hauteur de l'arbre comme variables se sont avérées appropriées pour l'usine de colombage, alors que les équations exponentielles l'étaient moins. Le modèle polynomial de deuxième ordre (modèle 2) avec DHP seulement est le modèle le plus approprié lorsque l'inventaire enregistre seulement le DHP, alors que le modèle polynomial de second ordre et le modèle fonction puissance impliquant 2 variables (DHP et hauteur de l'arbre pour l'usine variable et l'usine de colombage, respectivement, sont meilleurs lorsque le DHP et la hauteur de l'arbre sont disponibles.

caractéristiques de l’arbre / simulation du sciage / Optitek / rendement en sciages / modèle général

\section{INTRODUCTION}

Forest management in eastern Canada has long been focused on maximum stand yield (wood volume). It is known to both forest managers and sawmills that each cubic meter of wood does not produce the same yield in terms of product recovery.
This means that a volume-oriented forest management strategy does not necessarily lead to maximum product recovery and best return, as several recent studies [22, 23] have reported. As the forest industry in eastern Canada has been moving toward both intensive forest management and value-added products in recent years, it is becoming important that end uses and product

\footnotetext{
* Corresponding author: Tony.zhang@qc.forintek.ca
} 
Table I. Summary statistics of the 154 sample trees collected from a naturally regenerated jack pine precommercial thinning trial located in Miramichi, New Brunswick, Canada.

\begin{tabular}{lcccccc}
\hline & $\begin{array}{c}\text { DBH* } \\
(\mathrm{cm})\end{array}$ & $\begin{array}{c}\text { Total } \\
\text { height }(\mathrm{m})\end{array}$ & $\begin{array}{c}\text { Length below } \\
\text { live crown }(\mathrm{m})\end{array}$ & $\begin{array}{c}\text { Taper } \\
(\mathrm{cm} / \mathrm{m})\end{array}$ & $\begin{array}{c}\text { Stem volume up } \\
\text { to } 7 \mathrm{~cm}^{\left(\mathrm{m}^{3}\right)}\end{array}$ & $\begin{array}{c}\text { Merchantable } \\
\text { volume }\left(\mathrm{m}^{3}\right)\end{array}$ \\
\hline Mean & 16.4 & 15.3 & 10.1 & 1.0 & 0.1515 & 0.1367 \\
S.D. & 3.9 & 1.71 & 1.1 & 0.2 & 0.0808 & 0.0878 \\
Max. & 23.8 & 18.62 & 13.04 & 1.65 & 0.38117 & 0.37491 \\
Min. & 9.2 & 9.25 & 7.5 & 0.5 & 0.02879 & 0.00133 \\
\hline
\end{tabular}

* Outside bark DBH.

recovery be taken into consideration during forest management decision-making. To this end, it is necessary to develop treelevel models to predict product recovery based on tree characteristics collected for forest inventory.

It is well known that lumber recovery is closely related to some tree characteristics $[9,13]$. For decades, many studies $[8$, $11,14,17-19,25]$ have evaluated lumber recovery in relation to $\log$ characteristics such as log size, geometry and quality. Limited studies have assessed the effect of various tree characteristics on lumber recovery, including lumber volume [13], grade yield [1, 5] and product value [3, 9, 21, 24]. Most studies, however, were based on the product recovery from a specific sawmill. As a result, the models developed were only applicable to the specific layouts and conditions of the sawmills where the lumber conversions were carried out. The development of advanced sawing simulation packages in recent years (e.g. Optitek), however, has allowed researchers to define "standard sawmills" and thus simulate product recovery from these standard sawmills to develop general tree-level models.

The present study intended to develop general models to predict lumber recovery from individual trees using selected tree characteristics that are easy to measure and are usually collected for forest inventory. Jack pine (Pinus banksiana Lamb.), one of the most important commercial and reforestation species in Eastern Canada, was selected for this study. This species is highly valued for lumber and pulp production, and also holds great potential for intensive silviculture [10]. Optitek, a powerful sawing simulation package developed by Forintek Canada Corp. [6], was used to simulate lumber recovery. The sawing simulator has been validated and has been used intensively across Canada since 1994. It can be employed to simulate various operations in a softwood conversion mill, from bucking to optimized log breakdown, curved sawing, and optimized edging and trimming. Two state-of-the-art sawmills, a stud mill and an optimized random mill, were defined for eastern Canada to "process" the stems. A stud mill is a softwood sawmill which saws $8 \mathrm{ft}$ logs into studs, while a random mill (also called random length dimension mill) processes $8-16 \mathrm{ft}$ logs. Lumber recoveries from each type of sawmill in relation to key tree characteristics of diameter at breast height (DBH) and total tree height were examined to develop general treelevel lumber recovery models for jack pine. Based on the general models, product recovery from jack pine trees and stands could be estimated from forest inventory data. Thus, forest management decisions could be made in the context of product recovery to achieve specific objectives (e.g., maximum product yield, quality and value). A better understanding of the relationship between tree characteristics and lumber volume recovery will also help the sawmill industry to better plan for wood supply.

\section{MATERIALS AND METHODS}

\subsection{Sample selection}

A jack pine precommercial thinning (PCT) trial located at $47^{\circ} 01^{\prime}$ $59^{\prime \prime} \mathrm{N}, 65^{\circ} 01^{\prime} 00^{\prime}$ ' W on lower Miramichi, New Brunswick, Canada provided the sample trees for this study. The stands naturally regenerated from a fire in 1941. In 1966, when the stands were 25-years old, PCT was carried out and plots of different thinning intensities (spacings) were established by the New Brunswick Department of Natural Resources and Energy. In 2001, sample trees were collected from plots of 4 spacings (control, $4 \times 4,5 \times 5,7 \times 7 \mathrm{ft}$ ). From each spacing, 6 sample trees per DBH class were randomly selected to cover each merchantable DBH class at 2-cm intervals (e.g. 10, 12, 14, ..). Trees smaller than $10 \mathrm{~cm} \mathrm{DBH}$ class were not considered in this study because the minimum saw $\log$ diameter is $9 \mathrm{~cm}$ (able to produce a 2 by 3 stud). There were, however, an insufficient number of trees available in the largest DBH classes in each plot to reach the targeted 6 trees per DBH class. In total, 154 sample trees including 39 from the control, 39 from $4 \times 4,40$ from $5 \times 5$, and 36 from $7 \times 7$ spacing were collected. Table I presents the summary statistics for the 154 sample trees. The average tree DBH (outside bark) of $16.4 \mathrm{~cm}$ indicates that trees collected for this study were quite small.

\subsection{Tree measurements}

For each sample tree, the following tree characteristics were measured: outside bark $\mathrm{DBH}$, total tree length, tree length up to a $7-\mathrm{cm}$ diameter top, crown width in two opposite directions (North-South and East-West), crown length, clear log length, and diameters of the 5 largest branches on the trunk. Delimbed and debarked trees were scanned with a portable scanner to collect stem geometric data (true stem shape) at intervals of $10 \mathrm{~cm}$ along the stem. Geometric data included coordinates of cross-sections in 3-D space and diameters at both $\mathrm{X}$ and $\mathrm{Y}$ axes. The data were compatible with Optitek and were used for bucking and sawing simulations. The data were also used to determine stem taper, total stem volume and merchantable stem volume for each stem.

\subsection{Sawing simulation}

Data from the 154 scanned sample trees served as input for the Optitek sawmill simulations. Optitek is a sawing simulator developed by Forintek to "saw" a "real" shape log in different sawmill layouts 
Table II. Summary of the simulated lumber recovery for 154 sample trees from the stud mill and the optimized random mill using sawing simulator Optitek. Trees were sawn to produce a predefined product combination for various dimensions and grades with the highest lumber volume recovery.

\begin{tabular}{|c|c|c|c|c|c|}
\hline & $\begin{array}{c}\text { Product } \\
\text { dimension }\end{array}$ & $\begin{array}{l}\text { Length range } \\
\text { (ft) }\end{array}$ & $\begin{array}{l}\text { Number } \\
\text { of pieces }\end{array}$ & $\begin{array}{l}\text { Lumber volume } \\
\qquad(\mathrm{fbm} *)\end{array}$ & $\begin{array}{l}\text { Lumber value** } \\
\qquad \text { (CND \$) }\end{array}$ \\
\hline \multirow[t]{7}{*}{ Random mill } & $1 \times 3$ & $4-16$ & 187 & 397.25 & \\
\hline & $1 \times 4$ & $4-16$ & 192 & 636 & \\
\hline & $1 \times 6$ & $8-16$ & 0 & 0 & \\
\hline & $2 \times 3$ & $4-16$ & 264 & 1297.5 & \\
\hline & $2 \times 4$ & $4-16$ & 460 & 3543.33 & \\
\hline & $2 \times 6$ & $4-16$ & 110 & 1452 & \\
\hline & $2 \times 8$ & $8-16$ & 0 & 0 & \\
\hline Total & & & 1213 & 7326.08 & 2589.04 \\
\hline \multirow[t]{7}{*}{ Stud mill } & $1 \times 3$ & $4-8$ & 151 & 301.5 & \\
\hline & $1 \times 4$ & $4-8$ & 322 & 843 & \\
\hline & $1 \times 6$ & 8 & 0 & 0 & \\
\hline & $2 \times 3$ & $4-8$ & 276 & 1077.5 & \\
\hline & $2 \times 4$ & $4-8$ & 597 & 3131.33 & \\
\hline & $2 \times 6$ & $4-8$ & 55 & 422 & \\
\hline & $2 \times 8$ & 8 & 0 & 0 & \\
\hline Total & & & 1401 & 5775.33 & 1783.38 \\
\hline
\end{tabular}

* fbm is the short form of lumber volume unit "foot board measure" (also called "board foot"), equal to the amount of timber equivalent to a piece $12 " \times 12 " \times 1$ ".

** Lumber values were calculated based on 5-year (1998-2003) average market prices for green lumber as sold on the Toronto market [15] for specific dimensions and grades.

and product combinations. In this study, two state-of-the-art sawmills, a stud mill and an optimized random mill, were defined for eastern Canada to separately "saw" the 154 sample trees. In the stud mill, the stems were first bucked into logs of $2.44 \mathrm{~m}(8 \mathrm{ft})$ in length, and then $\operatorname{logs}$ were sent to the mill to be "cut" into lumber with optimized lumber volume recovery. In the random mill, the stems were first optimally bucked, and the optimized bucking solution was treated as the input of the sawmill where the logs were converted into lumber with the highest volume recovery. Consequently, products from the stud mill were primarily $2.44 \mathrm{~m}(8 \mathrm{ft})$ long studs, while products from the random mill ranged from 1.22 to $4.88 \mathrm{~m}$ ( 4 to $16 \mathrm{ft}$ ) in length. Lumber dimensions and grades were defined in a grade file for both sawmills.

\subsection{Simulation results}

Following proper sawmill equipment configuration, log data loading, and definition of product dimensions and grades, the process program was executed. Each tree was sawn into pre-defined product combinations. Then, Optitek generated a simulation report. In the report, product volume and value yields for each tree for both primary products (e.g. lumber) and by-products (e.g. chips) were given in the sections of volume and value performances. Bucking solutions and product summaries were also listed. Table II summarizes the lumber recovery and value returns from the 154 sample trees.

\subsection{Lumber conversion}

Actual lumber conversion for the 154 sample trees was carried out at a modern stud sawmill that parallels the typical stud mill defined for Optitek simulation. Each sample tree was bucked into 8-foot-long logs. The logs were sawn at a much slower speed than usual so that each piece of lumber and board from each log could be tracked. Lum- ber volume recovered from each sample tree was used to validate the models developed from the simulated sawing results.

\section{MODEL DEVELOPMENT}

To develop empirical models, it is necessary to select proper variables and model forms and to use good parameter estimation procedures and model validation techniques [7]. This study assumed that lumber volume recovery from an individual tree is a function of tree size (DBH and tree height) and tree geometry (taper), namely:

$$
V=f(D, H, T)
$$

where $V$ represents lumber volume (fbm) from a tree, $D$ denotes inside bark DBH $(\mathrm{cm}), H$ is total tree height $(\mathrm{m})$, and $T$ denotes stem taper $(\%)$ calculated based on tree height up to the $7-\mathrm{cm}$ diameter top.

Equation (1) can be extended to many forms. The plots of volume recovery against both $\mathrm{DBH}$ and total tree height (Fig. 1) suggest a non-linear relationship between lumber volume recovery and tree characteristics. This study considered three types of model forms: multiple polynomial function, exponential function and power function. Full third-order models with one, two and three variables were chosen for multiple polynomial models, respectively. Table III lists the different model forms examined with different variables. Models 2-4 considered the relationship of lumber volume recovery with DBH only, as many studies have reported that log diameter (DBH) contributes more to lumber volume recovery than other parameters such as tree height [24]. In Models 5-7, tree height 

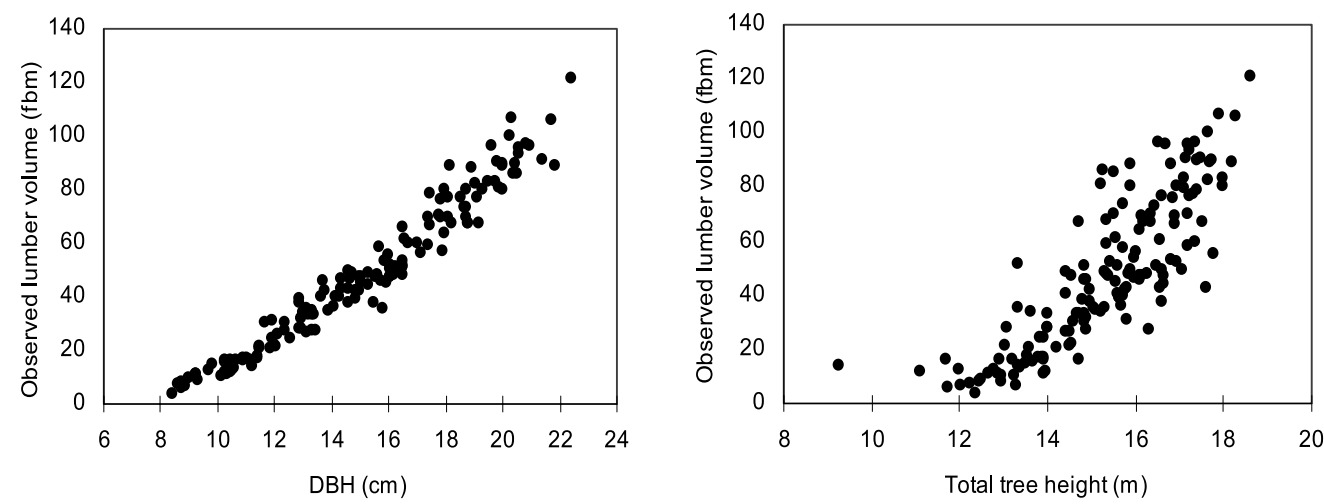

Figure 1. Observed (simulated using sawing simulator Optitek) lumber volume recovery in relation to DBH and tree height (in the case of the random mill) in jack pine.

Table III. Model forms for estimating lumber volume recovery using tree characteristics. Three variable combinations and three model forms were considered. The three combinations include (1) DBH only (Model 2-4); (2) DBH and total tree height (Models 5-7); and (3) DBH, total tree height and taper (Models 8-10). The three model forms include third-order multiple polynomial function, exponential function and power function.

\begin{tabular}{|c|c|}
\hline Model number & Model form \\
\hline 2 & $V=a_{0}+a_{1} D+a_{2} D^{2}+a_{3} D^{3}$ \\
\hline 3 & $V=a_{0}(D)^{a_{1}}$ \\
\hline 4 & $V=\exp \left(a_{0}+a_{1} D\right)$ \\
\hline 5 & $V=a_{0}+\sum_{i=1}^{3}\left(a_{i} D^{i}+b_{i} H^{i}\right)+\sum_{j=1}^{2} \sum_{k=1}^{2}\left(d_{j k} D^{j} H^{k}\right)$, where $j+k \leq 3$ \\
\hline 6 & $V=a_{0}(D)^{a_{1}}(H)^{a_{2}}$ \\
\hline 7 & $V=\exp \left(a_{0}+a_{1} D+a_{2} H\right)$ \\
\hline 8 & $V=a_{0}+\sum_{i=1}^{3}\left(a_{i} D^{i}+b_{i} H^{i}+c_{i} T^{i}\right)+\sum_{l} \sum_{j} \sum_{k}\left(d_{l j k} D^{l} H^{j} T^{k}\right)$ \\
\hline & where one of $j, l, k$ is zero, and the sum of the rest two of $j, l, k$ is not more than 3 . \\
\hline 9 & $V=a_{0}(D)^{a_{1}}(H)^{a_{2}}(T)^{a_{3}}$ \\
\hline 10 & $V=\exp \left(a_{0}+a_{1} D+a_{2} H+a_{3} T\right)$ \\
\hline
\end{tabular}

where $a_{i}, i=0,1,2,3, b_{\mathrm{i}}, \mathrm{i}=1,2,3, c_{i}, i=1,2,3, d_{i j k}, i=0,1,2, j=0,1,2, k=0,1,2$, are the coefficients of corresponding terms to be estimated. $D$, $H$ and $T$ denote DBH, total tree height and overall tree taper, respectively.

was added as a variable, and the interaction between the two variables was also considered in Model 5. Models 8-10 included stem taper as an additional variable. In Model 8, interactions among the three variables were considered as well. The purpose of adding variables one by one to the models was to examine the accuracy of those models with fewer tree variables involved and to see what is the least number or simplest combination of tree variables that can be used to precisely describe the relationship between lumber recovery and tree characteristics. This approach also allows for quantifying the contribution of added variable(s) to the goodness of the models.

In order to yield a proper interpretation of the data and to make the scales of the dependent and independent variables comparable [20], the polynomial Models 2, 5 and 8 were formulated in terms of deviation from the mean for each variable instead of directly using the original variable. The estimated 
Table IV. Stepwise selection results for third-order multiple polynomial regression models describing the relationship of volume recovery to different combinations of tree characteristics. All parameters were significant at the 0.05 significance level.

\begin{tabular}{lcl}
\hline Sawmill type & Model number & \multicolumn{1}{c}{ Fitted regression model* } \\
\hline Optimized random mill & 2 & $V=-19.319+1.127 D+0.21 D^{2}$ \\
& 5 & $V=43.517-0.105 D+0.214 D^{2}-9.163 H+0.401 H^{2}$ \\
\multirow{2}{*}{ Stud mill } & 8 & $V=15.764-1.354 D+0.114 D^{2}-2.881 H+0.339 D H-10.601 T$ \\
& 2 & $V=25.572-5857 D+0.42 D^{2}$ \\
& 5 & $V=65.859-6.716 D+0.423 D^{2}-5.858 H+0.259 H^{2}$ \\
& 8 & $V=11.935-8.189 D+0.617 \mathrm{D}^{2}+1.027 H+39.677 T-3.435 D T$ \\
\hline
\end{tabular}

* $D, H$ and $T$ denote inside bark DBH, total tree height and overall tree taper, respectively.

results were then transformed into the original variable. A stepwise selection process was applied to select the parameters that significantly affect the output. All 9 model forms were used to fit the entire data set using least square regression (LS) without data splitting to ensure prediction accuracy of the fitted models. The models were evaluated based on the calculated adjusted coefficient of determination $\left(R^{2}\right)$, the root mean square error (RMSE) and the significance. The predicted error sums of squares (PRESSs) of the 9 fitted equations were also evaluated in addition to the $R^{2}$ and RMSE. The PRESS was calculated by omitting the observed value for that observation, and thus served as an indicator of the goodness of a model. The PRESS statistic can be used to examine the stability of the parameters estimated as well. In addition, another statistic, maximum variance inflation factor (MVIF), was employed to evaluate the goodness of fit of a model. The variance inflation factor (VIF) is a common way to detect multicollinearity, which is a symptom of variance inflation. In a regression model, we aim to explain a high proportion of the variance (i.e. to produce a high $R^{2}$ ). The higher the level of variance explained, the better the model is. If collinearity exists, however, it is probable that the variance, standard error and parameter estimates will all be inflated. In other words, the high variance explained would not be a result of good independent predictors, but of a mis-specified model that carries mutually dependent and thus redundant predictors. A general rule is that the VIF should not exceed 10 [2]. The MVIF and PRESS are useful for examining if there is multicollinearity between independent variables in models and for choosing among different regression models for predictive purposes.

This paper examined three model forms that described the quantitative relationships between tree characteristics and lumber volume recovery. Based on selected statistical criteria, the quantification of these relationships will ensure that the candidate models developed are able to accurately and reliably forecast product volume from measured tree characteristics.

\section{RESULTS AND DISCUSSION}

Following stepwise selection, only the significant parameters in the three polynomial model forms are presented in Table IV. All parameters left in the models were significant at the 0.05 level. The stepwise selection results suggest that even for the same model forms, the effects of tree characteristics on lumber recovery may be different depending on sawmill type. For example, for Model 8, the fitted regression model for the optimized random mill was a second-degree polynomial equation including three variables with a pure quadratic term of $\mathrm{DBH}$, three linear terms and an interaction term between $\mathrm{DBH}$ and tree height, while in the case of the stud mill the polynomial model (Model 8) took the same form but the interaction term was between DBH and tree taper. This suggests that these three variables are somewhat dependent, and that the effect of one variable on lumber volume recovery per tree may depend on the others.

The regression results between lumber recovery and tree characteristics for the 9 model forms are listed in Table V. For all model forms for both sawmill types, $R^{2}$ values were greater than 0.90 , indicating that at least $90 \%$ of the total variation in the tree lumber volume recovery could be explained by tree characteristics contained within the models. For both sawmills, Model 8 had the highest $R^{2}$ value of 0.97 , while Model 4 had the lowest $R^{2}$ of 0.910 and 0.934 for the stud and optimized random sawmills, respectively. As shown in Table V, the exponential function models (Models 4, 7 and 10) in both mills had the lowest $R^{2}$ values, whereas the polynomial model forms (Models 2, 5 and 8) had the highest $R^{2}$ values. However, the differences in $R^{2}$ values between the polynomial models and the power models with different variables involved were small and could be of little practical importance. This suggests that power models perform as well as polynomial models if considering $R^{2}$ value alone. The PRESSs of the 9 models ranged from 3157.3 to 10269 for the stud mill and from 3572.4 to 20150 for the random mill. The smallest and largest PRESSs were for Models 8 and 4, respectively, for both mills. RMSEs ranged from 4.713 to 11.230 for the random mill and from 4.396 to 8.020 for the stud mill. MVIFs ranged from 1.0 to 3.48 for models with two variables, indicating that multicollinearity was not present; for models with three variables, the MVIFs were over 9.0 , suggesting severe collinearity among variables in the models. All parameters in each model were statistically significant at the 0.05 level with an exception being tree taper in Model 10 for both mills and Model 9 for the random mill. This suggests over-parameterization for these exponential and power models [4]. In other words, adding stem taper into models which already included both DBH and tree height as variables would not significantly improve the goodness of the models because 
Table V. Parameter estimates and statistical criteria for the 9 models using least square regression. Two types of sawmills were considered. Four criteria were used to evaluate models.

\begin{tabular}{|c|c|c|c|c|c|c|c|c|c|}
\hline \multirow{2}{*}{$\begin{array}{l}\text { Type of } \\
\text { sawmill }\end{array}$} & \multirow[t]{2}{*}{ Model } & \multicolumn{4}{|c|}{ Parameters $^{1}$} & \multicolumn{4}{|c|}{ Criteria } \\
\hline & & $a_{0}$ & $a_{1} / b_{1} / c_{1}^{2}$ & $a_{2} / b_{2}$ & $a_{3} / d_{1}$ & $R^{2}$ & RMSE & PRESS & MVIF \\
\hline \multirow{9}{*}{ 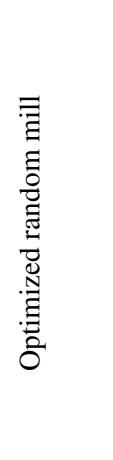 } & 2 & -19.319 & 1.127 & 0.21 & & 0.958 & 5.592 & 4937.7 & 1.0 \\
\hline & 3 & $0.019(0.00 * *)^{3)}$ & $2.851(0.00 * *)$ & & & 0.954 & 7.183 & 8079.1 & 1.0 \\
\hline & 4 & $0.721(0.00 * *)$ & $0.195(0.00 * *)$ & & & 0.910 & 11.230 & 20150 & 1.0 \\
\hline & 5 & 43.517 & $-0.105 /-9.163$ & $0.214 / 0.401$ & & 0.967 & 4.773 & 3645.8 & 3.48 \\
\hline & 6 & $0.003(0.00 * *)$ & $2.467(0.00 * *)$ & $0.998(0.00 * *)$ & & 0.962 & 6.235 & 6123.1 & 3.14 \\
\hline & 7 & $-0.253(0.1308)$ & $0.154(0.00 * *)$ & $0.103(0.00 * *)$ & & 0.929 & 9.943 & 15861 & 3.06 \\
\hline & 8 & 15.764 & $-1.354 /-2.881 /-10.601$ & $0.114 / 0$ & 0/0.339 (DH) & 0.970 & 4.713 & 3572.4 & 11.05 \\
\hline & 9 & $0.003(0.00 * *)$ & $2.637(0.00 * *)$ & $0.880(0.00 * *)$ & $-0.146(0.182)$ & 0.962 & 6.244 & 6145.4 & 10.79 \\
\hline & 10 & $-0.319(0.101)$ & $0.147(0.00 * *)$ & $0.109(0.00 * *)$ & $0.103(0.502)$ & 0.928 & 9.870 & 15646 & 9.93 \\
\hline \multirow{9}{*}{ 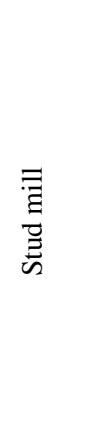 } & 2 & 25.572 & -5.857 & 0.42 & & 0.961 & 4.988 & 3978.6 & 1.0 \\
\hline & 3 & $0.006(0.00 * *)$ & $3.170(0.00 * *)$ & & & 0.960 & 5.049 & 3985.9 & 1.0 \\
\hline & 4 & $0.069(0.347)$ & $0.219(0.00 * *)$ & & & 0.934 & 8.020 & 10269 & 1.0 \\
\hline & 5 & 65.859 & $-6.716 /-5.858$ & $0.4233 / 0.259$ & & 0.967 & 4.614 & 3247.4 & 3.48 \\
\hline & 6 & $0.002(0.00 * *)$ & $2.855(0.00 * *)$ & $0.817(0.00 * *)$ & & 0.964 & 4.687 & 3445.8 & 3.14 \\
\hline & 7 & $-0.761(0.00 * *)$ & $0.184(0.00 * *)$ & $0.088(0.00 * *)$ & & 0.944 & 7.392 & 8746.1 & 3.06 \\
\hline & 8 & 11.935 & $-8.189 / 1.027 / 39.677$ & $0.617 / 0$ & 0/-3.435 (DT) & 0.970 & 4.396 & 3157.3 & 11.05 \\
\hline & 9 & $0.001(0.00 * *)$ & $3.126(0.00 * *)$ & $0.629(0.00 * *)$ & $-0.232\left(0.047^{*}\right)$ & 0.965 & 4.529 & 3219.8 & 10.79 \\
\hline & 10 & $-0.753(0.00 * *)$ & $0.185\left(0.00^{* *}\right)$ & $0.087(0.00 * *)$ & $-0.012(0.934)$ & 0.944 & 7.424 & 8829.5 & 9.92 \\
\hline
\end{tabular}

${ }^{1}$ Estimated polynomial model forms 2, 5 and 8 for both random mill and stud mill are presented in Table IV.

2 Slashes between values for Models 5 and 8 separate coefficients for the same order variables.

${ }^{3}$ Figures in parentheses represent probability levels $(*$ denotes significance at $p<0.05$ and $* *$ denotes significance at $p<0.01)$. Letters in parentheses represent variables. The coefficient of these variables are presented to the right. For example, the coefficient for variable $(D H)$ in Model 8 for the optimized random mill was 0.339. All parameters for Models 2, 5 and 8 were significant at $p<0.05$.

stem taper in jack pine has been reported to be very closely related to DBH and tree height [16].

It must be noted that the developed models in this study apply to jack pine trees of a DBH up to $24 \mathrm{~cm}$. As shown in Tables IV and V, the variables in either fitted polynomial or power models were between second or fourth power. This suggests that the predicted lumber recovery using these models increase dramatically with increasing tree size. Therefore, further research is needed to consider larger tree sizes. It should also be noted that the models were developed based on the tree diameter at exact breast height, namely, diameter at tree height of $1.3 \mathrm{~m}$ from the ground. Therefore, any inaccurate DBH data may result in inaccurate prediction of tree lumber volume recovery.

\subsection{Lumber recovery in relation to $\mathrm{DBH}$}

Diameter is the most commonly measured tree parameter because it is a very important tree characteristic and the easiest to measure. If a model is developed to accurately predict lumber recovery using DBH only, product recovery could be estimated based on any DBH data inventory. Models 2-4 were the 3 forms describing the relationship of lumber recovery with $\mathrm{DBH}$ for individual trees. As shown in Table V, DBH alone was able to explain 90.9-95.8\% and 93.5-96.1\% of the variation in lumber volume recovery from the optimized random mill and stud mill, respectively.

\subsubsection{Scenario 1 optimized random mill}

As shown in Table $\mathrm{V}$, the $R^{2}$ value of the fitted seconddegree polynomial model (Model 2) was as high as 0.958 , while the power model (Model 3) and the exponential model (Model 4) had $R^{2}$ values of 0.954 and 0.91 , respectively. This indicates that the exponential model was less suitable for describing the relationship of interest. Moreover, the fitted exponential equation also had a much higher RMSE and PRESS than did Model 2. Model 3 performed better than Model 4 in terms of $R^{2}$, RMSE and PRESS. However, in spite of having a $R^{2}$ value similar to that of Model 2, Model 3 was not as good as Model 2 in terms of RMSE and PRESS. Using $R^{2}$ as a criterion for discriminating competitive models can be very hazardous [12]. Besides criteria like $R^{2}$ and PRESS, the plots of the predicted residuals should be examined as well. 

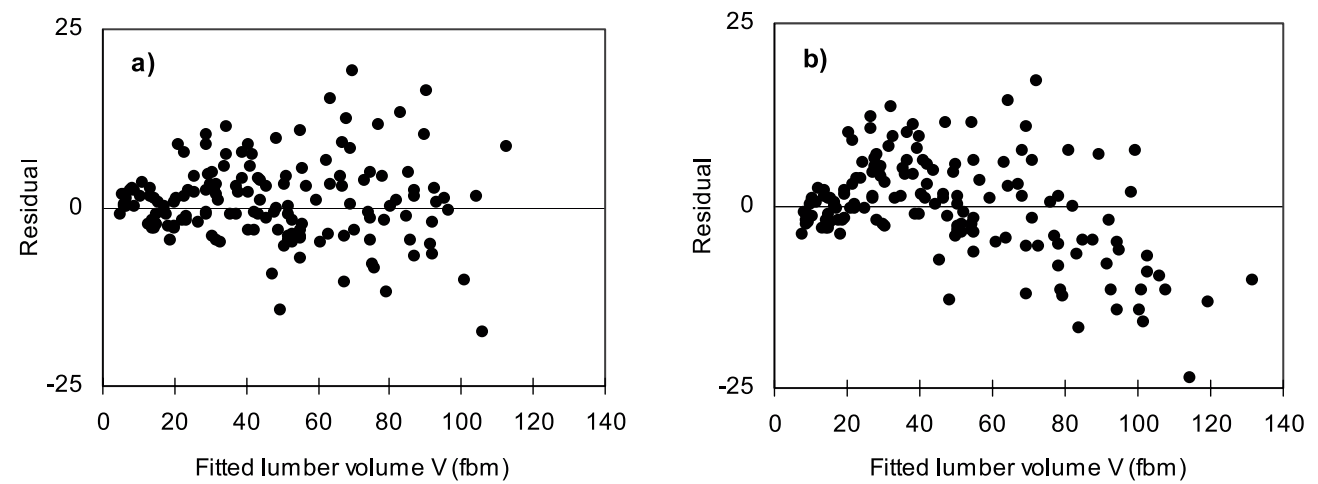

Figure 2. Plots of residuals against fitted lumber volume recovery in the case of the random mill in jack pine. (a) Model 2 (second-order polynomial model with one variable "DBH"); (b) Model 3 (power model with one variable "DBH").
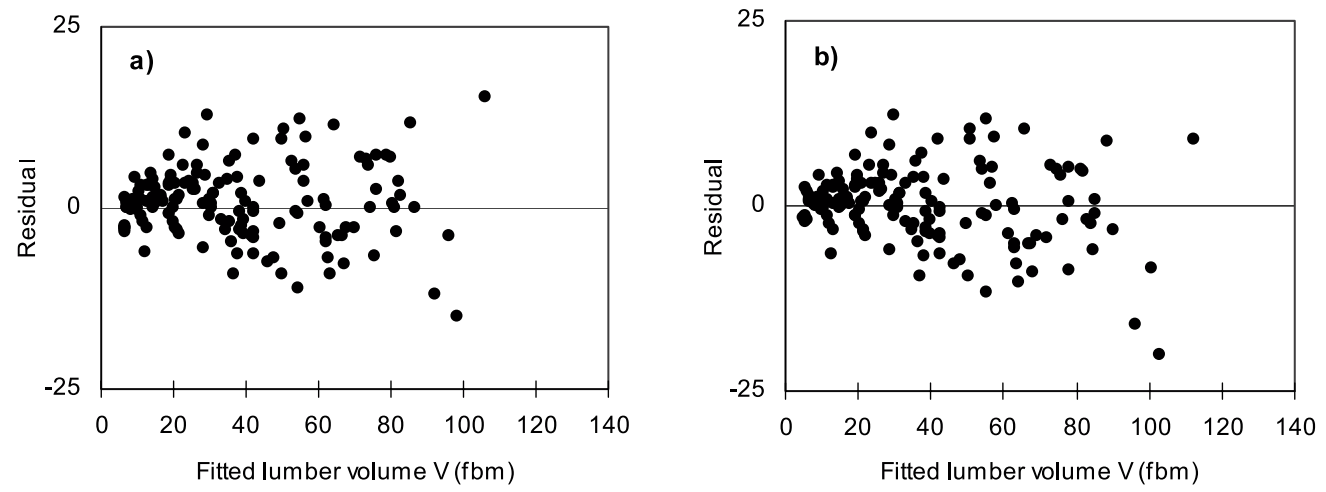

Figure 3. Plots of residuals against fitted lumber volume recovery in the case of the stud mill in jack pine. (a) Model 2 (second-order polynomial model with one variable "DBH"); (b) Model 3 (power model with one variable "DBH").

Figure 2 illustrates the predicted residuals against the fitted lumber recovery for the random mill for Models 2 and 3. Model 2 had a more evenly distributed residual plot over the fitted lumber volume than did Model 3. The residuals were evenly and symmetrically spread on both sides of the zero line for Model 2, while Model 3 showed a systematic residual distribution pattern to some extent. Therefore, Model 2 was the most reliable in predicting lumber recovery from the optimized random mill when only DBH was considered as a variable. The predicted residual plot for Model 2 appeared to have a wider residual range in the right side than in the left side. Figure 1 presents the plots of the measured DBH and tree height against the observed lumber volume recovery form the random mill. Lumber volume recoveries from trees of small DBH classes varied within a relatively narrow range, while the volume recoveries from trees of large DBH classes were scattered in a wider range. A similar trend was noticed for lumber volume recovery against tree height. This indicates that lumber volume recovery from a larger tree was more variable than from a smaller tree. As a result, predicting lumber recovery for larger trees tended to be less accurate.

\subsubsection{Scenario 2 stud mill}

In the case of the stud mill, Model 2 also had the highest $R^{2}$ value, followed by Model 3, whereas Model 4 had the lowest
$R^{2}$ value (Tab. V). However, the difference in $R^{2}$ values between Models 2 and 3 was very small and was likely inconsequential, particularly because differences in RMSE and PRESS between Models 2 and 3 were also very small. The predicted residual plots (Fig. 3) against the fitted lumber recovery also illustrated that Models 2 and 3 had almost identical residual distribution patterns and that the residuals were evenly distributed over the range of fitted lumber volumes. Despite having a $R^{2}$ value of as high as 0.93 , Model 4 had much higher RMSE and PRESS compared to Models 2 and 3 (Tab. V), suggesting less accurate prediction by the exponential model. Therefore, statistically Models 2 and 3 were both adequate in estimating jack pine lumber volume recovery from the stud mill using DBH only.

\subsection{Lumber recovery in relation to DBH and tree height}

Tree height is another important tree characteristic affecting lumber recovery. It depends on site index and is often recorded for forest inventory, although not as easily as DBH. Models 5-7 in Tables IV and V described lumber volume recovery in relation to both DBH and tree height.

\subsubsection{Scenario 1 Optimized random mill}

The estimated polynomial equation (Model 5) with the two variables of DBH and total tree height is presented in Table IV. 


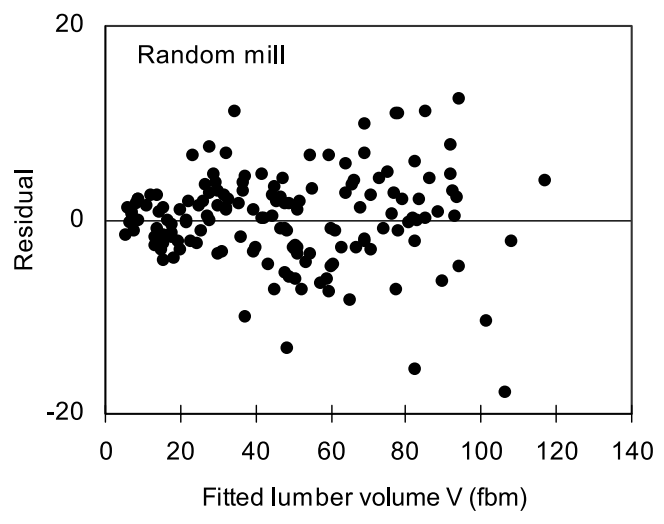

Figure 4. Plot of residuals against fitted lumber volume for Model 5 (second-order polynomial model with two variables "DBH and tree height") in the case of the optimized random mill in jack pine.

Estimated parameters for the pure quadratic terms of DBH and tree height were highly significant, while the parameters for the third order terms and for the cross product of $\mathrm{DBH}$ and tree height were not statistically significant at the 0.05 level. This implies that tree height and DBH both have a quadratic effect on lumber volume recovery from the random mill. Model 5 had a $R^{2}$ value of 0.97 , higher than those of both Models 6 and 7 , and its RMSE and PRESS were considerably lower. The exponential model (Model 7) may not be considered appropriate due to its prominent RMSE and PRESS even though its $R^{2}$ value was high at 0.929 . Similarly to Model 3 for the random mill, the power model (Model 6) had a fairly comparable $R^{2}$ value and appreciably higher RMSE and PRESS than the polynomial model (Model 5), indicating less suitability as a predictor. As shown in Figure 4, the plot of residuals against fitted lumber volume recovery for Model 5 showed that the residuals were randomly scattered on both sides of the zero line. Therefore, Model 5 was adequate for predicting jack pine lumber volume recovery from the random mill using DBH and total tree height.

\subsubsection{Scenario 2 stud mill}

In the case of the stud mill, Model 5 also had the highest $R^{2}$ value and lowest RMSE and PRESS, followed by Model 6, whereas Model 7 had the lowest $R^{2}$ value and greatest RMSE and PRESS (Tab. V). Again, as seen with Models 2 and 3 for the stud mill, the difference between Models 5 and 6 was quite small for all three criteria. The exponential model had a high $R^{2}$ of 0.944 , however, it was less suitable than Models 5 and 6 due to its much higher RMSE and PRESS. Therefore, Models 5 and 6 were considered statistically adequate for predicting lumber volume recovery from the stud mill using two tree characteristics (DBH and tree height). For the fitted Model 5 for the stud mill, there were 5 terms including the intercept and two quadratic terms in the model. Thus, Model 6 may be preferable from a practical viewpoint because it was simpler than Model 5. Figure 5 illustrates the difference between the observed and the fitted lumber volumes for Models 5 and 6. Overall, Model 6 seemed to perform as well as Model 5. The two models were able to accurately predict lumber recovery from small trees (e.g. less than $90 \mathrm{fbm} /$ tree). However, both models less accurately estimated lumber volume recovery from big trees (e.g. over $90 \mathrm{fbm} /$ tree). Figure 6 depicts the curve performances of the two models relating tree lumber volume recovery to its $\mathrm{DBH}$. The curves present the effect of tree $\mathrm{DBH}$ on lumber volume recovery while holding tree height at an average level of $15.3 \mathrm{~m}$. Again, Figure 6 showed that Model 6 appeared to be as good as Model 5. Model 6 could accurately predict the lumber recovery for small trees (up to $18 \mathrm{~cm}$ at DBH), whereas Model 5 showed an overestimation for trees under $12 \mathrm{~cm}$ at $\mathrm{DBH}$, and both models underestimated the lumber volume recovery from big trees (e.g., over $20 \mathrm{~cm}$ at DBH).

\subsection{Lumber recovery in relation to $\mathrm{DBH}$, tree height and tree taper}

Models 8-10 in Table V described lumber volume recovery in relation to three tree characteristics including stem taper. Derived from multiple polynomial functions, Model 8 included both pure quadratic terms and interactive terms. Parameters for the third order terms were not significant at 0.05 probability
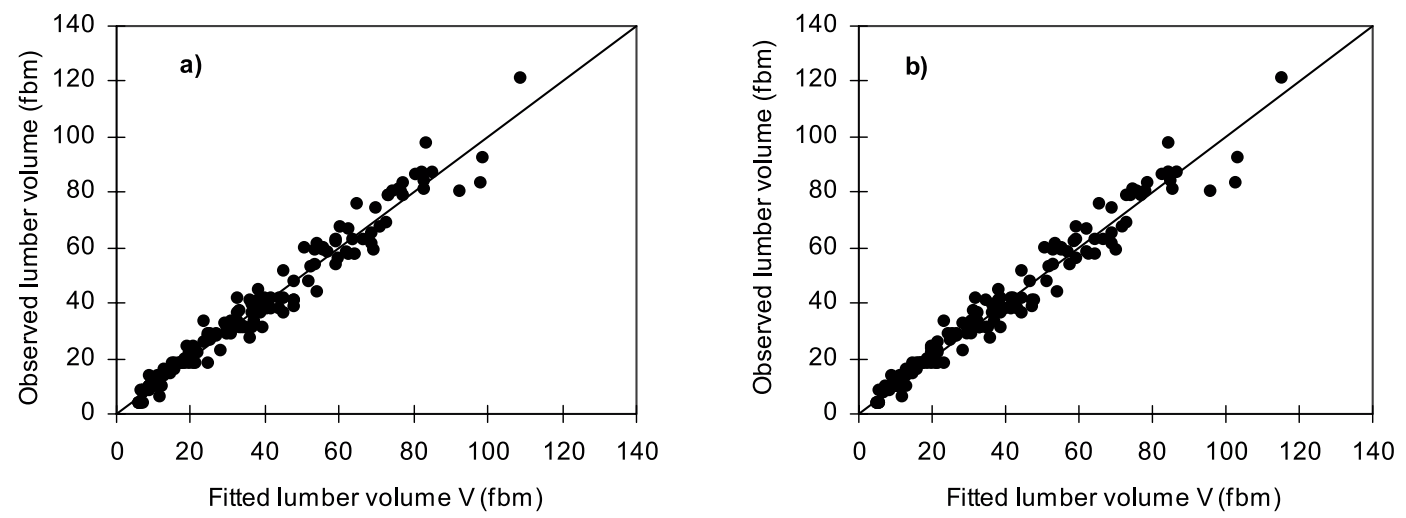

Figure 5. Observed (simulated using sawing simulator Optitek) lumber volume against predicted lumber volume in the case of the stud mill in jack pine. (a) Model 5 (second-order polynomial model with two variables "DBH and tree height"); (b) Model 6 (power model with two variables "DBH and tree height"). 

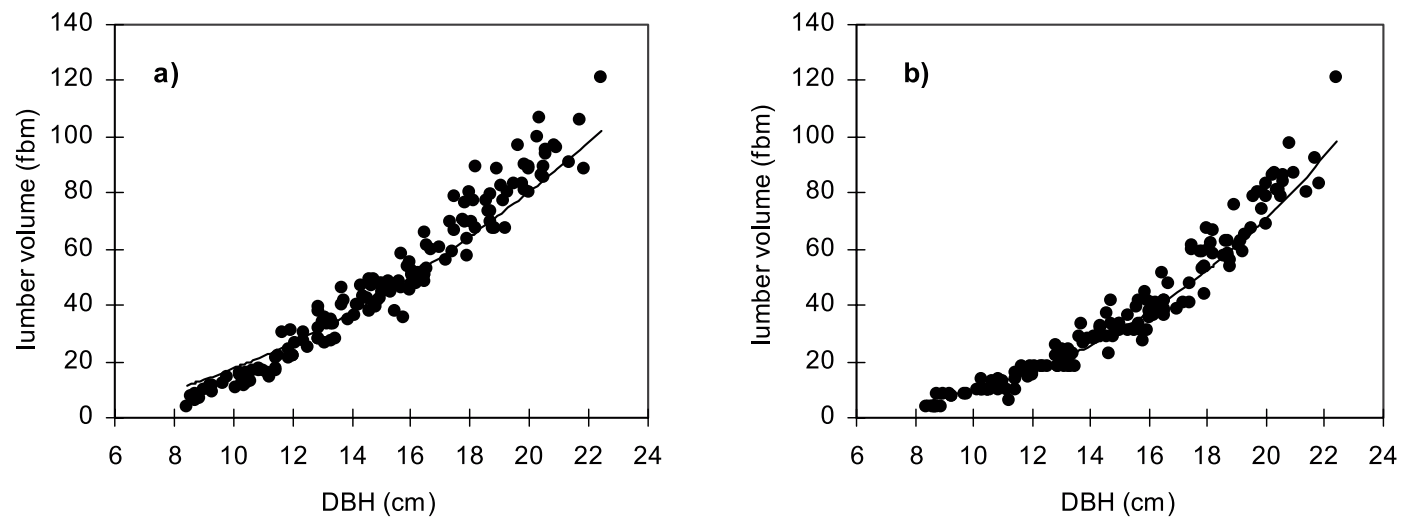

Figure 6. Predicted lumber volume recovery of jack pine for the stud mill in relation to DBH while holding tree height at an average level of $15.3 \mathrm{~m}$. (a) Model 5 (second-order polynomial model with two variables "DBH and tree height"); (b) Model 6 (power model with two variables "DBH and tree height").

Table VI. ANOVA analysis results for testing the fitness of candidate models for the stud mill using data from a real stud sawmill.

\begin{tabular}{lcccccc}
\hline & Max. (fbm) & Min. (fbm) & Mean (fbm) & StDev & $T$ Stat. & $p$ value \\
\hline Sawmill & 99.58 & 3 & 38.77 & 22.18 & & \\
Model 2 & 105.34 & 6.22 & 37.707 & 24.71 & 0.5933 & 0.5539 \\
Model 3 & 108.88 & 6.39 & 37.701 & 24.79 & 0.6240 \\
Model 5 & 112.26 & 5.35 & 37.703 & 25.65 & 0.5383 & 0.5536 \\
Model 6 & 115.66 & 5.29 & 37.671 & 25.43 & 0.6192 \\
\hline
\end{tabular}

level following stepwise selection for both mills; for the random mill, the effect of tree DBH on lumber volume recovery was dependent on the total tree height, while for the stud mill the DBH effect depended on tree taper, and vice versa. Compared with Model 5, Model 8 (including the additional variable of tree taper) did not seem to provide an appreciable improvement in either $R^{2}$ value or RMSE and PRESS. In contrast, with the additional variable tree taper, the MVIF increased from 3.48 to 11.05 for both mills, which implies the presence of severe multicollinearity among the three variables in Model 8. A similar trend was observed in Model 9 for the stud mill. It therefore made sense to omit the variable tree taper from the model specification even though the variable appeared statistically significant. On the other hand, the significance levels of the parameters estimated for tree taper in Models 9 and 10 were 0.182 and 0.502 , respectively, in the case of the random mill, and 0.047 and 0.934 , respectively, in the case of the stud mill. This indicates that, statistically, tree taper should be excluded from the models as its impact on lumber volume recovery was not significant except for Model 9 for the stud mill, where tree taper could be omitted due to the high variation inflation as stated above. This seemed to be inconsistent with the common sense viewpoint that stem taper has a negative impact on tree product recovery. It is well known that tree taper depends on DBH and tree height. As a matter of fact, a taper equation developed by Sharma and Zhang [16] for jack pine using only DBH and total tree height is able to accurately estimate diameter profile, explaining over $95 \%$ of the variation. Therefore, it was not surprising that adding tree taper to Models 9 and 10, which already included both DBH and tree height, would not significantly improve the goodness of fit of the models. Overall, the three model forms with three variables including tree taper did not seem suitable for predicting the lumber volume recovery from the both sawmills.

\subsection{Model validation}

As discussed above, Models 2 and 5 for the random mill and Models 2, 3, 5 and 6 for the stud mill were considered to better describe lumber volume recovery in relation to the selected tree characteristics. Actual lumber volume recovery data of the 154 sample trees sawn in a real stud sawmill were used to further validate the 4 models for the stud mill. The summary statistics and paired T-test results for means for sawmill data and predicted data using the 4 models are presented in Table VI. The significance levels ( $p$ values) for the differences between lumber volume recoveries from the real stud sawmill and from the 4 models were $0.554,0.554,0.591$ and 0.537 for Model 2, 3,5 and 6 , respectively. This suggests that there are no statistically significant differences between the predicted lumber volume recovery and the actual volume recovery from the real stud sawmill, thus all 4 models are able to accurately predict lumber volume recovery. It appeared that all 4 models somewhat overestimated the real lumber recovery from the largest trees. This may happen as the largest trees usually come from wider spacings where more jack pine trees contain severe stem deformations. Overall, all 4 models slightly under-predicted lumber volume recovery. This might be due to the fact that the 
actual size of green lumber produced in the real stud sawmill was slightly smaller than that configured for the stud sawmill in the sawing simulator Optitek.

\section{CONCLUSION}

Using statistical methods, three model forms and their extensions with different variables involved in two types of sawmills were studied for their ability to predict lumber volume recovery from basic tree characteristics. The results demonstrated that the polynomial function form was the most suitable for predicting lumber volume recovery from the random mill, followed by the power function, while for the stud mill the power and polynomial function forms were both good for describing lumber volume recovery from tree characteristics. The results also indicate that the exponential functions were the least suitable. For both sawmills, a second-order polynomial function with one variable, DBH, was able to explain as much as $95.83 \%$ of the total variation for the optimized random mill and $96.1 \%$ for the stud mill. Adding tree height to the model led to a small but significant increase in the percentage of the variation explained. The power function form for the stud mill performed as well as the polynomial function form. The power function may be preferable for predicting lumber volume recovery from the stud mill using DBH and tree height, as it was simpler. The study also indicates that adding tree taper to a model including $\mathrm{DBH}$ and tree height did not improve the goodness of fit of the model as tree taper in jack pine can be well described by DBH and total tree height. The second-order polynomial model (Model 2) with DBH alone could be used to accurately predict lumber volume recovery from both stud and random mills when inventory records DBH only, while the second-order polynomial model (Model 5) and the power model (Model 6) involving two variables (DBH and tree height) were better for the random mill and the stud mill, respectively, when both DBH and tree height are recorded for forest inventory.

\section{REFERENCES}

[1] Beauregard R.L., Gazo R., Ball R.D., Grade recovery, value, and return-to-log for the production of NZ visual grades (cuttings and framing) and Australian machine stress grades, Wood Fiber Sci. 34 (2002) 485-502.

[2] Belsley D.A., Kuh E., Welsch R.E., Regression Diagnostics, John Wiley and Sons, New York, NY, 1980.

[3] Briggs D.G., Tree value system: description and assumptions, General Technical Report Pacific Northwest Research Station, USDA Forest Service, No. PNW-GTR-239, 1989, 24 p.

[4] Draper N.R., Smith H., Applied regression analysis, 2nd ed., John Wiley and Sons, New York, 1981.

[5] Fahey T.D., Grading second-growth Douglas-fir by basic tree measurements, J. For. 4 (1980) 206-206.
[6] Forintek Canada Corp., Optitek: User's guide, Forintek Canada Corp., Sainte-Foy, Quebec, 1994, 185 p.

[7] Gujarati D.N., Basic econometrics, 3rd ed., McGraw-Hill, New York, 1995

[8] Harless T.E.G., Wagner F.G., Steele P.H., Taylor F.W., Yadama V., McMillin C.W., Methodology for locating defects within hardwood logs and determining their impacts on lumber-value yield, For. Prod. J. 41 (1991) 25-30.

[9] Kellogg R.M., Warren W.G., Evaluating western hemlock stem characteristics in terms of lumber value, Wood Fiber Sci. 16 (1984) 583-597.

[10] Law K.N., Valade J.L., Status of the utilization of jack pine (Pinus banksiana) in the pulp and paper industry, Can. J. For. Res. 24 (1994) 2078-2084.

[11] Middleton G.R., Munro B.D., Log and lumber yields, in: Kellogg R.M. (Ed.), Second-growth Douglas-fir: its management and conversion value, Special Publication, No. SP-32, Forintek Canada Corp., Vancouver, BC, 1989.

[12] Myers R.H., Classical and modern regression with applications, PWS-KENT, Boston, Massachusetts, 1989.

[13] Oberg J.C., Impacts on lumber and panel products, Proceedings of Southern Plantation Wood Quality Workshop, June 6-7, 1989, Athens, Georgia.

[14] Pnevmaticos S.M., Flann I.B., Petro F.J., How log characteristics relate to sawing profit, Canadian Forest Service, Can. For. Industries No. 1, 1971, 4 p.

[15] Quebec Forest Industry Council. 2002 - the yearbook, Economics \& Markets Department, Quebec Forest Industry Council, Quebec, Canada, 2003.

[16] Sharma M., Zhang S.Y., Variable exponent taper equation for jack pine, black spruce and balsam fir in eastern Canada, For. Ecol. Manage. 198 (2004) 39-53.

[17] Shi R., Steele P.H., Wagner F.G., Influence of log length and taper on estimation of hardwood BOF position, Wood Fiber Sci. 22 (1990) 142-148.

[18] Steele P.H., Factors determining lumber recovery in sawmilling, General Technical Report FPL-39, Forest Products Laboratory, Madison, Wisconsin, 1984.

[19] Wagner F.G., Taylor F.W., Lower lumber recovery at southern pine sawmills may be due to misshapen sawlogs, For. Prod. J. 43 (1993) $53-55$.

[20] Yu C.H., Centered-score Regression/SAS tips, [on-line] Available URL: $\mathrm{http} / / /$ seamonkey.ed.asu.edu/ alex/computer/sas/s_regression.html, 1998.

[21] Zhang S.Y., Chauret G., Ren H.Q., Desjardins R., Impact of plantation black spruce initial spacing on lumber grade yield, bending properties and MSR yield, Wood Fiber Sci. 34 (2002) 460-475.

[22] Zhang S.Y., Chauret G., Swift E., Maximizing the value of jack pine through intensive forest management, CFS Rep. No. 3171, Forintek Canada Corp., Sainte-Foy, Quebec, 2001.

[23] Zhang S.Y., Corneau Y., Chauret G., Impact of precommercial thinning on tree and wood characteristics, product quality and value in balsam fir, Canadian Forest Service No. 39, Forintek Canada Corp., Sainte-Foy, Quebec, 1998, 77 p.

[24] Zhang S.Y., Lei Y.C., Modeling the relationship of product value of individual trees with tree characteristics in black spruce, Forest Sci. (submitted).

[25] Zheng Y., Wagner F.G., Steele P.H., Ji Z.D., Two-dimensional geometric theory for maximizing lumber yield from logs, Wood Fiber Sci. 21 (1989) 91-100. 